\title{
Genetic Parameters Derived From Using a Biological Model of Lactation on Records of Commercial Dairy Cows
}

\author{
B. Albarrán-Portillo* and G. E. Pollott $\dagger^{1}$ \\ ${ }^{*}$ Centro Universitario Temascaltepec, Universidad Autónoma del Estado de México, Carretera Toluca-Tejupilco Km. 67.5, C.P. 51300, México \\ †Royal Veterinary College, Royal College Street, London, NW1 OTU, United Kingdom
}

\begin{abstract}
The object of this study was to investigate the genetics of lactation curve parameters derived from a biological model of lactation and the relationships among them. This biological model fitted 2 logistic curves to mimic the initial increase in milk secretory cell numbers in early lactation and the progression of apoptosis in late lactation. Records from 82,255 Holstein-Friesian heifers from commercial dairy herds in the United Kingdom, recorded from 1994 to 2003, were analyzed. The heritabilities of 2 lactation curve parameters, maximum secretion potential and relative cell death rate, were 0.27 and 0.08 respectively. Maximum secretion potential was highly genetically correlated with peak yield (0.99), and relative cell death rate was highly correlated with persistency of lactation (0.84). Heritability values for the traits analyzed showed a characteristic pattern. Total milk yield traits, maximum secretion potential, and peak yield had similar and moderate heritabilities ( 0.3). Traits associated with late lactation had lower heritability values $(\sim 0.1)$, whereas day of peak yield and early lactation traits had little genetic variation. The permanent environmental variance of the various traits ranged from 0.08 to 0.26 of the phenotypic variance. Parameters from the 2 logistic curves were not highly correlated, suggesting that selection programs could be devised to exploit genetic variation in both aspects of lactation independently.
\end{abstract}

Key words: biological model, dairy cow, genetic parameter, lactation curve

\section{INTRODUCTION}

Milk production during lactation from dairy animals has been widely studied using a range of mathematical models (Masselin et al., 1987). These models have evolved from the early incomplete gamma function suggested by Wood (1967) to more sophisticated meth-

Received December 7, 2007.

Accepted May 21, 2008.

${ }^{1}$ Corresponding author: gpollott@rvc.ac.uk ods, such as random regression models (Schaeffer and Dekkers, 1994) or spline models (White et al., 1999; Misztal, 2006). In general, these empirical models produce parameters of curves that mimic milk production throughout lactation (Olori et al., 1999).

Characteristics of the lactation curve have been described by the coefficients of these various models. The incomplete gamma function proposed by Wood (1967) has been the most widely used model to fit the lactation curve (Olori et al., 1999). This model accounts for the main parameters of the lactation curve such as milk yield at the start of lactation, rate of increase to peak yield, and persistency of lactation. These parameters, and in general parameters from any other lactation curve model, show genetic variation, allowing selection for desired characteristics of the lactation curve (Batra et al., 1987) and for particular lactation curve shapes (Togashi and Lin, 2006, 2007).

The empirical models mentioned above produce parameters by fitting equations, but, ultimately, milk production is a biological process based on the number of secretory cells and secretion rate per cell throughout lactation (Pollott, 2000). A biological approach to lactation curve models was proposed by Dijkstra et al. (1997) and Pollott (2000). The latter outlined a biological model that described the curve parameters in terms of secretory cell differentiation in early lactation, cell death rate after parturition, and a change in secretion rate per cell during lactation. This approach was based on the dynamics of the mammary cell population as described by Knight and Wilde (1993), Wilde et al. (1997), and Knight et al. (1998).

The parameters derived from the biological model cover some of those described by Wood (1967) as well as three new proposed parameters: Maximum secretion potential (MS), a function of the total number of parenchyma secretory cells and the maximum secretion rate (kg/cell per day), the relative growth rate in cell numbers from parturition to peak yield, and the relative death rate in cell numbers from mid to the end of lactation.

Since it was first proposed, the biological model has been developed to make it suitable to fit lactations with 
as few as 4 test-day records. Versions of the biological model with 2 and 3 parameters were compared with the model of Wood, in its linear and nonlinear form, the model of Grossman and Koops (1988) (Pollott and Gootwine, 2000) and Morant and Gnanasakthy (1989). The results showed that the biological models fitted dairy sheep lactations with a smaller or similar residual mean square than the other models with the same number of parameters.

The biological model has been used to study the genetics of the lactation curve of Awassi sheep. Pollott and Gootwine (2001) reported the genetics of the new parameters proposed, as well as information about the phenotypic and genetic correlations of curve parameters using this approach. In dairy cows, the model has been used to describe the lactation curve parameters (Pollott, 2000) and to describe, in biological terms, the secretion of milk and its components [i.e., fat, protein, lactose, total solids, and water (Pollott, 2004)]. However, this model has not been used to determine the genetics of the curve parameters with data from commercial dairy cows. Hence, the objective of this study was to determine the genetics of, and the relationship among, parameters of the lactation curve of dairy cows using a biological model of lactation on records from commercial dairy cow herds.

\section{MATERIALS AND METHODS}

\section{Data}

The data used in this research was derived from a large database provided by National Milk Records Ltd. (Chippenham, UK) from commercial dairy herds in the United Kingdom. A total of 392,954 lactations from 190,739 cows were initially chosen from the largest herds recorded between 1994 and 2003. Lactations used in this analysis were edited as follows: those that had the first test day recorded after d 80 of lactation were deleted, as were lactations with $<4$ test-day records. Cows younger than 20 mo of age or older than 40 mo of age at first calving were deleted. Subsequently, cows without a known sire and dam were discarded.

After editing, 353,502 lactations of 161,799 cows from 431 herds remained in the data set, of which 82,255 were first lactations. Numbers of test-day records per lactation ranged from 4 to 15 , with an average of 10 test-day records per lactation.

\section{Model}

Lactation curves were fitted to the data using the 2-parameter multiplicative model suggested by Pollott (2000) and used for the first time by Pollott and
Gootwine (2000). This is an alternative to the original 7-parameter multiplicative model (Pollott, 2000), which would have had the difficulty of fitting a model with 7 parameters to farm-recorded monthly test-day records. The 2-parameter model was:

$$
M_{t}=\underbrace{\left(M S /\left\{1+z e^{[-0.1(t-150)]}\right\}\right)}_{\mathrm{S}_{a} \times \mathrm{NDPC}} \underbrace{\left\{2-e^{[D R(t-150)]}\right\}}_{\mathrm{PR}}
$$

where $M_{t}=$ milk yield on day $t$ of lactation; $M S=$ the maximum secretion potential of the lactation; $z=[(1-$ 0.9999999)/0.9999999]; and $D R=$ the relative decline in cell numbers as lactation progresses (Pollott and Gootwine, 2000, 2001). Basically, the model comprised 2 logistic curves (Figure 1). The first curve accounted for the increase in cell numbers during early lactation as a function of time. Specifically, the first part of the equation estimated MS as the maximum secretion rate of milk as the product of the average secretion rate per cell $\left(\mathrm{S}_{a}\right)$ and the number of differentiated parenchyma cells (NDPC). The second logistic curve determined the down slope of the lactation (after peak yield) due to the relative death rate of cells as a function of time, the proportional reduction in cell numbers (PR) as lactation progresses (Pollott, 2000).

\section{Curve Fitting}

Curves were fitted to each of the 353,502 lactations using the 2-parameter biological model with an iterative nonlinear curve-fitting procedure (NLIN) in SAS (SAS Institute, 1999). The iterative process was initiated using preliminary estimates of the parameters [e.g., $\mathrm{MS}=0.1$ to 85 (bounds $0<\mathrm{MS}<85$ ) and $\mathrm{DR}=0.0001$ to 0.1 (bounds $-1<\mathrm{DR}<1$ )]. The best fit of the model with respect to a particular lactation was obtained when the difference between the residual sums of squares in successive iterations was $<10^{-6}$.

\section{Curve Parameters}

The parameters derived from fitting the 2-parameter model to each of the 353,502 lactations were complemented with calculated values describing various features of the lactation curve. These were the daily increase in milk production midway from the start of lactation to peak yield; peak yield; day of peak yield; persistency, which was estimated at the midpoint between peak yield and the end of lactation; total milk yield; calculated total milk yield; and lactation length (Pollott, 2000). Total milk yield was the lactation milk yield calculated from the original test-day records using the test-interval method of Sargent et al. (1968). 


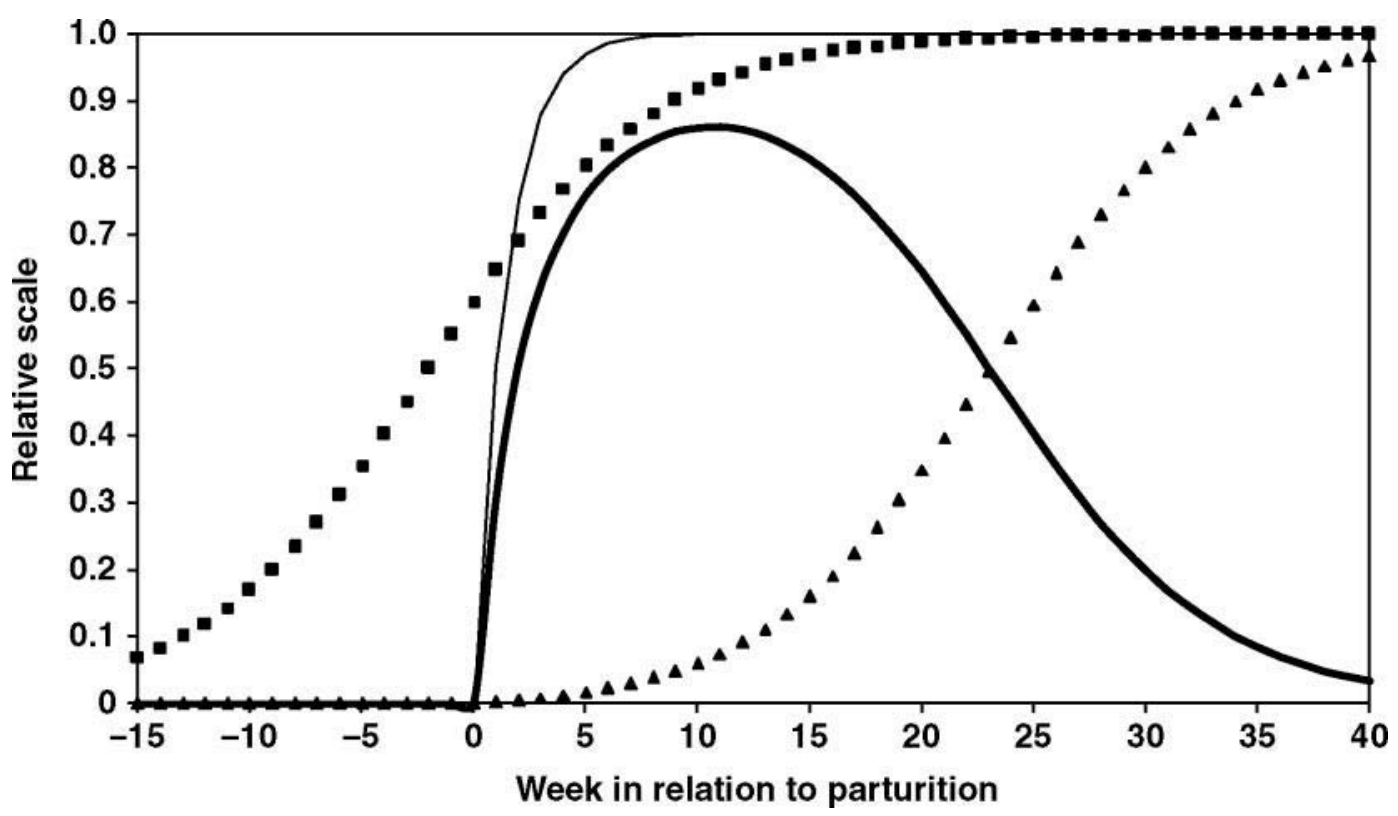

Figure 1. A schematic diagram of the lactation curve showing the essential features of the biological model. The number of differentiated parenchyma cells ( - ) combines with the cell secretion rate (-) to give the maximum secretion potential of the mammary gland. The proportion of active cells dying due to apoptosis $(\mathbf{\Lambda})$ decreases the number of active cells in mid to late lactation. The number of active cells multiplied by the cell secretion rate gives the milk yield (一).

Calculated total milk yield was the lactation milk yield calculated from the parameters of the biological model (Pollott, 2000) as the area under the lactation curve.

\section{Analyses}

An animal model was used to estimate the heritability of first-lactation curve parameters and traits. The 3 -generation pedigree file contained 9,342 sires and 125,272 dams. Univariate analyses were carried out, and heritabilities and standard errors of all traits were estimated using ASREML (Gilmour et al., 2002).

The animal model used was:

$$
Y_{i j k l m}=\mu+H Y S_{i}+A F C_{j}+L l_{k}+A_{l}+e_{i j k l m},
$$

where $\mathrm{Y}_{i j k l m}=$ observation for each curve trait; $\mu$ = overall mean; $H Y S_{i}=$ the fixed effects for herd-year-season with 9,360 levels; $A F C_{j}=$ the regression of age at first calving; $L l_{k}=$ the regression of lactation length; $A_{l}=$ the random effect of animal $(\mathrm{n}=82,255)$; and $e_{i j k l m}=$ residual variation.

Heritability was calculated as the ratio of estimated additive genetic variance $\left(\sigma_{a}^{2}\right)$ to estimated phenotypic variance $\left(\sigma_{p}^{2}\right)$. Genetic and phenotypic correlations were estimated using bivariate analyses in ASREML (Gilmour et al., 2002) using equation [2] for each pair of traits. It was not possible to compute bivariate analy- ses with the 3-generation pedigree using the available computational resources, so it was decided to work with a 1-generation pedigree file to estimate the genetic and phenotypic correlations, as well as the repeatability of the traits. The 1-generation pedigree file contained 4,672 sires and 68,776 dams.

Repeatability of the various traits was estimated separately from 2 different data sets. The first data set used all available subsequent records from the cows used in the initial genetic analysis (i.e., lactations 1,2 , 3 , and $>3$ from the same animal). This analysis obviously excluded first-lactation cows with only 1 record and, thus, was based on a slightly decreased number of cows. Animals included in this analysis averaged 2.3 lactations per cow. The second data set used all lactation records used in the first data set plus lactations from all cows that had repeated records, but did not have first-lactation records available. The average number of lactations in the second data set was 2.2 lactations per cow. The model used for the repeatability analyses was similar to equation [2] but with an additional fixed effect of lactation number and random effect for the permanent environmental variance associated with repeated records of the animal. Also, the age at first-calving covariate was fitted within lactation number. Repeatability was calculated as the sum of the estimated additive genetic variance and the estimated permanent environmental variance divided by the phenotypic variance. Standard errors were calculated as described by Gilmour et al. (2002). 
Table 1. Mean and standard deviation (SD) of 8 traits used in the genetic analyses

\begin{tabular}{|c|c|c|c|c|}
\hline Trait & \multicolumn{2}{|c|}{ First lactation } & \multicolumn{2}{|c|}{ All other lactations } \\
\hline Maximum secretion potential (kg/d) & 30.1 & 5.1 & 39.5 & 8.3 \\
\hline Peak yield (kg/d) & 28.7 & 5.0 & 37.1 & 7.7 \\
\hline Day of peak yield (d) & 34.6 & 7.0 & 33.7 & 15.1 \\
\hline Relative rate of decline in cell numbers & 0.001 & 0.0004 & 0.002 & 0.0004 \\
\hline Total milk yield (kg) & 7,609 & 1,310 & 8,548 & 2,621 \\
\hline
\end{tabular}

\section{RESULTS}

The means and standard deviations of the 8 traits analyzed are shown in Table 1 for first and all other recorded lactations. First lactations had lower total milk yields than those from older cows $(7,609$ vs. $8,548 \mathrm{~kg})$. This difference was achieved by older lactations having a greater peak yield $(28.7 \mathrm{vs} .37 .1 \mathrm{~kg} / \mathrm{d})$ despite a lower persistency (a loss of $47.7 \mathrm{vs} .89 .7 \mathrm{~g} / \mathrm{d}$ ). The greater peak yield of lactations from the older cows was the result of a greater increase in daily milk yield in early lactation (151 vs. $232 \mathrm{~g} / \mathrm{d})$. All traits were found to be more variable when measured on older cows than heifers. The mean, range, and standard deviation of age at first calving and lactation length, the 2 traits used as covariates in the first-lactation animal models, were 28.7, 19.5 to 40.5 and $5.74 \mathrm{mo}$, and 319,97 to 450 and $67.3 \mathrm{~d}$, respectively. All fixed, regression, and random terms used in the models had a significant effect on all the traits $(P<0.001)$.

\section{Effect of Age at Calving and Lactation Length on the Lactation Traits}

Table 2 has the regression coefficients and their standard errors for age at first calving and lactation length with the lactation traits. An increase in age at first calving by 1 mo increased total milk yield and cal- culated total milk yield by 46.5 and $48 \mathrm{~kg}$, respectively. Persistency declined by $0.68 \mathrm{~g} / \mathrm{d}$ as age at calving increased by 1 mo. Increments in age at first calving had a positive effect over the rest of the traits, with the exception of day of peak yield, which was decreased by $0.03 \mathrm{~d}$ as age at first calving increased.

An increase in lactation length by $1 \mathrm{~d}$ increased total milk yield and calculated total milk yield by 23.4 and, $23.1 \mathrm{~kg}$, respectively. Milk production became slightly more persistent as lactation length increased, by 0.07 $\mathrm{g} / \mathrm{d}$. Increasing lactation length decreased the daily milk production midway between calving and peak yield by $0.12 \mathrm{~g} / \mathrm{d}$ and also relative cell death rate by $0.24 \mathrm{e}^{-05}$.

\section{Heritability}

Table 3 has the additive genetic and residual variances and heritabilities of the lactation curve traits from the univariate analyses, using both 3 generations and 1 generation in the pedigree. Heritability estimates ranged from 0.03 (day of peak yield) to 0.34 (total milk yield).

Comparing the heritability values from both models, there were no big differences in values estimated with the 3 -generation pedigree compared with the 1-generation pedigree. The differences were never greater

Table 2. Regression coefficients (RC) and their standard errors for age at first calving and lactation length for each lactation curve trait analyzed

\begin{tabular}{|c|c|c|c|c|}
\hline Trait & \multicolumn{2}{|c|}{ Age at first calving (mo) } & \multicolumn{2}{|c|}{ Lactation length (d) } \\
\hline Maximum secretion potential $(\mathrm{kg} / \mathrm{d})$ & 0.23 & $0.62 \mathrm{e}^{-02}$ & $0.42 \mathrm{e}^{-02}$ & $0.2 \mathrm{e}^{-03}$ \\
\hline Peak yield $(\mathrm{kg} / \mathrm{d})$ & 0.21 & $0.58 \mathrm{e}^{-02}$ & $0.63 \mathrm{e}^{-02}$ & $0.26 \mathrm{e}^{-03}$ \\
\hline Day of peak yield (d) & -0.03 & $0.84 \mathrm{e}^{-02}$ & 0.01 & $0.38 \mathrm{e}^{-03}$ \\
\hline Relative rate of decline in cell numbers & $0.76 \mathrm{e}^{-05}$ & $0.49 \mathrm{e}^{-06}$ & $-0.24 \mathrm{e}^{-05}$ & $0.22 \mathrm{e}^{-07}$ \\
\hline Total milk yield (kg) & 46.5 & 1.59 & 23.4 & 0.07 \\
\hline
\end{tabular}


than $2 \%$ for any trait. The heritability values for total milk yield, calculated total milk yield, peak yield, and MS were regarded as moderately high (0.28 to 0.34), whereas those for day of peak yield, persistency, relative death rate of cells, and increase in daily milk yield in early lactation were considered to be low $(<0.12)$.

\section{Genetic Correlations}

The genetic and the phenotypic correlations among the traits are in Table 4. The standard errors were low, ranging from 0.001 to 0.093 . The genetic correlations among maximum secretion potential, peak yield, and the 2 total milk yield traits were near 1 . Genetic correlations of the daily change in milk yield midway between the start and peak of lactation with most of the other parameters were high, particularly with maximum secretion potential, peak yield, and persistency. The main exception was with day of peak yield. Day of peak yield was moderately correlated with both total milk yield traits and with persistency. Peak yield was highly correlated with the 2 total milk yield traits, moderately correlated with persistency, and negatively correlated with the relative death rate of cells. Genetic correlations of the relative death rate of cells with the 2 total milk yield traits were both negative. Finally, persistency was highly correlated with early lactation change in milk yield and the relative death rate of cells. The rest of the correlations involving persistency were moderate, both positive and negative.

\section{Phenotypic Correlations}

The phenotypic correlations ranged from -0.51 to 1.00 (Table 4). The phenotypic correlations of MS with early lactation change in milk yield, peak yield, persistency, and both total milk yield traits were high and in general had similar trends compared with the genetic correlations. The daily change in milk yield midway between the start and peak of lactation was highly correlated with maximum secretion potential, peak yield, the relative death rate of cells, and persistency; the correlation of daily change in milk yield midway between the start and peak of lactation with both total and calculated milk yield was moderate and negatively correlated with day of peak yield.

Day of peak was lowly correlated with both milk yield traits and negatively correlated with the rest of the traits. Peak yield was highly correlated with most of the traits, other than day of peak, with which it was negatively correlated. Relative cell death rate had a high phenotypic correlation with early lactation increase in milk yield and persistency. In both cases, the phenotypic correlations were greater than 
Table 4. Genetic (above the diagonal) and phenotypic (below the diagonal) correlations among lactation curve traits (standard errors shown below in parentheses)

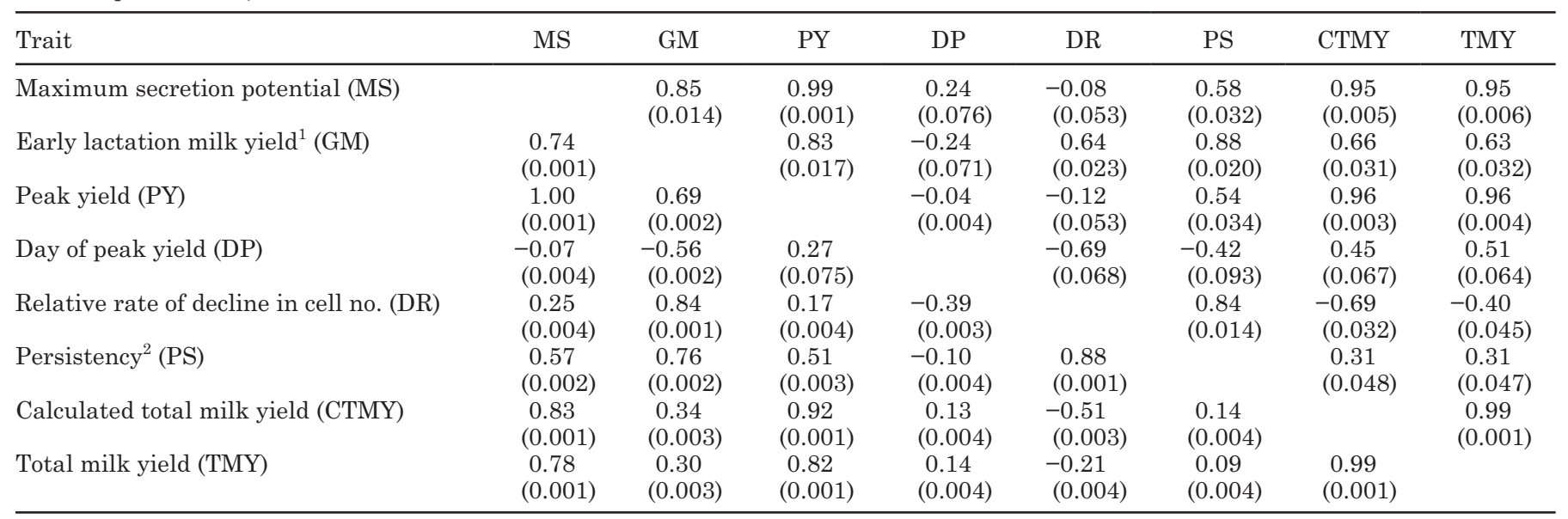

${ }^{1}$ Change in milk yield midway between the start and peak of lactation.

${ }^{2}$ Loss in yield midway between the peak and end of lactation.

the genetic correlations. The same trend was repeated for cell death rate and maximum secretion potential, although lower in scale. In the case of day of peak yield and the 2 total milk yield traits, the correlations with relative cell death rate were negative. Persistency was highly correlated with maximum secretion potential, early lactation change in milk yield, peak yield, and cell death rate, whereas it showed a negative correlation with total milk yield. Finally, both total milk yield traits were highly correlated with each other and with MS and peak yield. They were strongly correlated with early lactation milk yield but poorly correlated with day of peak yield and persistency.

\section{Repeatability}

Table 5 has the permanent environmental variance as a proportion of the phenotypic variance and the repeatability of the curve traits for all cows that had heifer records, used in the genetic analysis, that also had repeated records (i.e., lactations 1, 2, 3, and $>3$ ). Repeatability ranged from 0.20 (relative cell death rate) to 0.51 (total milk yield and calculated total milk yield), whereas the permanent environmental variance as a proportion of the phenotypic variance ranged from 0.08 (daily change in milk yield in early lactation) to 0.19 (day of peak yield).

Table 5 also has the permanent environmental variance as a proportion of the phenotypic variance and repeatability from the additional data set that included all animals with repeated records, regardless of whether their first lactation was missing or not. The permanent environmental variance proportion ranged from 0.12 (MS and change in milk yield midway between the start and peak of lactation) to 0.26 (day of peak yield), whereas repeatability ranged from 0.25 (persistency) to 0.52 (total milk yield and calculated total milk yield). In general, both proportion of perma-

Table 5. Permanent environmental variance proportion $\left(\mathrm{c}^{2}\right)$ and repeatability $(\mathrm{t})$ of cows with repeated records ${ }^{1}$

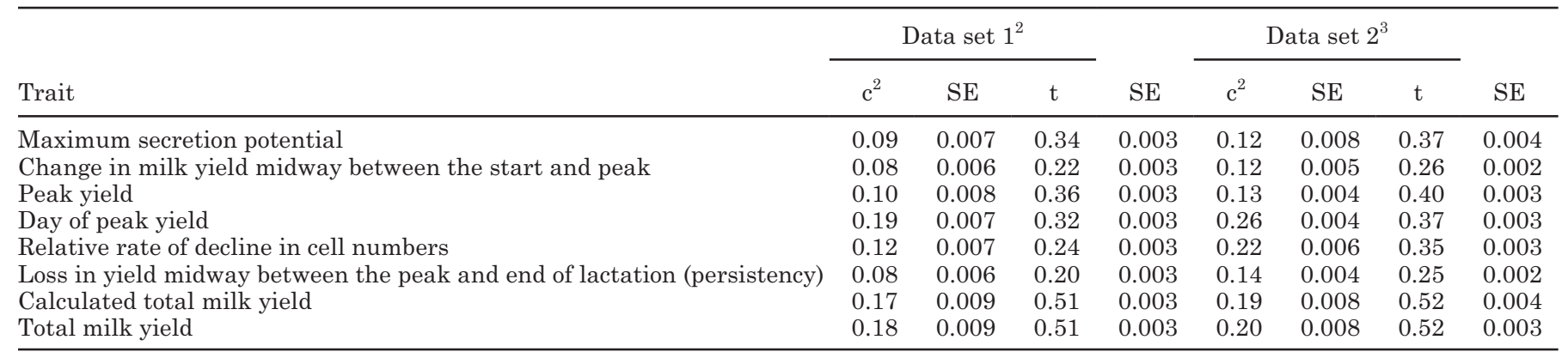

${ }^{1}$ Standard errors are shown after the individual estimates.

${ }^{2}$ Data from cows that had first-lactation records.

${ }^{3}$ Data from all available cows. 
nent environmental variance and repeatability of the traits in the second data set were greater than the corresponding values from the first data set, based on the heifers used in the genetic analyses.

\section{DISCUSSION}

The fundamental principle underlying the development of a biological model of lactation (Pollott, 2000, 2004) was to produce a model that had biologically meaningful parameters. This contrasted with the empirical approach widely used in lactation curve work (Wood, 1967) where parameters often had little biological explanation. It also contrasts with test-day methodology using random regression that models the lactation curve very accurately but provides little explanation of what is happening to the animal. Using the biological model of lactation, it is possible to discuss the different features of the lactation curve in terms of what is happening in the mammary gland of the animal. It also prompts further research questions phrased in terms that biologists of different specialties can understand and relate to.

Pollott and Gootwine (2000) investigated the use of a reduced version of the biological model, as suggested by Pollott (2000), because it was more appropriate to monthly commercial test-day records. They discussed the use of a model with a range of parameters from 2 to 5 and highlighted the advantages and disadvantages of each. In the current study, the 2-parameter multiplicative model was chosen, because it is most applicable to dairy cow records that tend to have lactations that terminate well before the natural end to lactation. This allows an alternative form of the decreasing phase logistic curve to be used with 1 less parameter (Pollott, 2000). There was little point in using a model that attempts to model the increasing phase accurately, because the number of records at the beginning of lactation was limited.

The 2-parameter multiplicative model estimates the MS and relative cell death rate from the data. These 2 parameters are used to calculate peak yield, day of peak yield, persistency, the rate of increase in milk production midway between the start and peak of lactation, and the calculated total milk yield of the lactation. This provides 7 traits for analysis plus the total milk yield estimated by the test-interval method (Sargent et al., 1968).

\section{Genetic Parameters of the Biological Model of Lactation}

Heritability. Genetic studies of the type reported here commonly look to similar studies to achieve jus- tification of their results or demonstrate the degree of similarity. Heritability values depend on a range of factors and are really only relevant to the population from which they were derived (Falconer and Mackay, 1996). Hence, comparison with other published results may or may not be useful, depending on the circumstances of the estimates, and there is really no formal method for comparison.

In a study such as this, what may be of more interest are the relativities between different aspects of the results. Two sets of comparisons are obvious here: the relative heritabilities of the several traits and the relationships between the traits as shown by the correlations.

Table 3 , in which all heritability estimates had a standard error $<0.01$, indicated that total milk yield had the greatest heritability (0.34) and was only slightly larger than calculated total milk yield (0.32). The MS (0.28) and peak yield (0.30) had slightly lower values than the total yield traits but were in the same range. No other trait had a heritability close to these values. The 2 traits associated with the declining phase of the lactation had heritabilities of 0.08 , whereas the daily milk yield midway between the start and peak of lactation had a heritability of 0.12 . Day of peak yield had a value near zero. This pattern of relative heritabilities was similar to that reported by G. Pollott (unpublished data) in a study of heifers in a single herd. In that study, the heritabilities of peak yield and MS were similar (0.34 and 0.30, respectively) and they in turn were similar to calculated total milk yield (0.34). In an analysis of Awassi sheep lactation curves, Pollott and Gootwine (2001) found the same pattern, albeit at a lower level, with all 3 traits having a heritability within $2 \%$ of each other. G. Pollott (unpublished data) reported a lower heritability for the 2 traits associated with the declining phase of lactation: 0.18 for the relative death rate of cells in late lactation and 0.11 for persistency. However, Pollott and Gootwine (2001) found values of 0.04 and 0.11 for these 2 traits. Day of peak yield was found to have a low heritability by both Pollott and Gootwine (2001) and G. Pollott (unpublished data). The overall pattern of these results appears to be that milk yield, peak yield, and MS are all similarly and moderately heritable. Traits associated with the declining phase of lactation are less heritable than the yield traits, whereas early lactation traits and day of peak yield have very little genetic control at all.

The majority of other studies investigating the genetics of lactation curve parameters have been based on the incomplete gamma function of Wood (1967). This model has 3 parameters relating to the level of production at the start of lactation (a), the rate of increase in early lactation (b), and the rate of decrease in 
late lactation (c). These parameters also can be used to estimate peak yield, day of peak yield, persistency, and total milk yield. The parameter a of Wood, a scaling factor, has no equivalent in the model of Pollott (2000). Parameters b and c of Wood are similar to the daily change in early lactation milk yield and the persistency measure calculated from the biological model, respectively. Batra et al. (1987) estimated heritability for total milk yield of 0.41 , peak yield of 0.23 , week of peak yield of 0.18 , persistency of 0.21 , and the parameters $b$ and c of Wood with values of 0.07 and 0.04 . Other authors also report low heritability values for the parameters of Wood's curve (Schneeberger, 1981; Shanks et al., 1981; Farhangfar, 2002), but the relative values of the other traits differ. All reports seem to have a moderate value for peak yield but a much greater value for total milk yield, with the exception of Farhangfar (2002), who found similar values. Whether this is due to the known difficulties of the incomplete gamma function to fit accurately around the peak of lactation (Pollott and Gootwine, 2000) or other aspects of the difference between the 2 models is difficult to say.

Correlations. Considering the genetic correlations in Table 4, the relationship between peak yield and MS was almost unity, suggesting that they are either the same trait or controlled by almost the same genes; the former is most likely, because the phenotypic correlation was also unity. In addition, these 2 traits were highly correlated (0.95) with the 2 total milk yield traits, suggesting that the genes that determine overall milk yield also regulate peak yield-maximum secretion potential. The phenotypic correlations between the peak traits and the total milk yield traits ranged from 0.78 to 0.92 , indicating that there were environmental factors that determined a small part of the relationship between the 2 sets of traits. The 2 peak traits (peak yield and maximum secretion potential) had genetic correlations with the other 6 traits, which only differed from each other by $<0.04$. They were highly correlated with the daily change in milk yield midway between the start and peak of lactation (0.83 and 0.85 , respectively), were moderately correlated to persistency ( 0.54 and 0.58 , respectively), but had no relationship with the relative rate of cell decrease in late lactation.

This pattern of genetic correlations was reflected in the studies by Pollott and Gootwine (2001) and G. Pollott (unpublished data); in both cases, MS was very highly correlated with peak yield, and both of these traits were highly correlated with total milk yield. The relationship between the peak traits and late-lactation traits was less clear cut. Pollott (2008) reported a moderate negative correlation between the peak traits and relative death rate of cells but no correlation with persistency, whereas Pollott and Gootwine (2001) found no relationship with relative death rate but a strong correlation with persistency.

The relative rate of decline in cell numbers showed a high genetic correlation with persistency (0.84). A similar genetic correlation was found by Pollott and Gootwine (2001) among the same traits (0.81) on the Awassi lactation curve. Persistency and relative cell death rate are traits that are of interest because of the trends in genetic selection toward longevity and extended lactations.

Reports from authors using the incomplete gamma function also found very high genetic correlations between peak and total milk yield (Batra et al., 1987; Farhangfar, 2002). Peak yield was also highly correlated with parameter $b$ of Wood and moderately correlated with persistency (Batra et al., 1987). Most other correlations (Shanks et al., 1981; Batra et al., 1987; Farhangfar, 2002) were similar to those reported in this study and confirmed the pattern of correlated relationships found here.

Repeatability. Most traits had a similar level of permanent environmental effect as a proportion of the phenotypic variance $(\sim 0.1)$, but the 2 total milk yield traits and day of peak yield had greater levels $(\sim 0.18)$. In most cases, the level of genetic control was greater than the permanent environmental effect, with the exception of day of peak yield and persistency. Thus, the differences found between individuals for the various traits will largely be passed on to their offspring.

The 2 total milk yield traits were highly repeatable $(\sim 0.51)$, much more so than any of the other traits analyzed in this study. Maximum secretion potential, peak yield, and day of peak yield were moderately repeatable $(\sim 0.34)$, but the former 2 traits had a greater level of genetic control than day of peak. The remaining traits had a low repeatability $(\sim 0.20)$. Traits with a low repeatability are influenced more by factors, which vary from lactation to lactation. Thus, the traits dealing with changes in milk yield during lactation were much more subject to variation between lactations than the total milk yield traits.

\section{A Biological Interpretation of the Genetics of Lactation Curves}

Maximum secretion potential is the product of the maximum number of secretory cells active during the lactation and the average maximum secretion rate of secretory cells, 2 measures that cannot yet be differentiated using commonly recorded data. The development of a method to separate these 2 key features of MS would be a major breakthrough in the application of the biological model of lactation to dairy genetics. In addition, parameters of the biological model have been 
used to estimate several features of lactation curves, most of which can be estimated from other models.

Although the biological model, as it is used in this work, is unable to separate secretion rate from the number of active secretory cells, there are several environmental factors that affect daily milk production. Vetharaniam et al. (2003) tested their model of the mammary gland against results from system studies and demonstrated how the daily milking frequency and different nutritional levels may affect both components of maximum secretion potential. There is a regulatory mechanism involving a feedback inhibitor of lactation (Wilde et al., 1995), the application of which mimics both the effect of milking frequency on milk secretion rate and a sequential change in cellular differentiation, which maintains the secretory response. The feedback mechanism of lactation is likely to alter cell secretion rate, but the level of secretory cell engorgement also has the potential to switch an alveolus between its active and quiescent states (Davis et al., 1999).

Maximum secretion potential is a critical aspect of lactation. It was found to be highly genetically correlated with total lactation milk yield, as well as the measures of the change in milk yield both in early and late lactation. These latter 2 relationships are not really surprising, because a greater MS will mean a faster increase in early lactation and a steeper decrease in late lactation for daily milk yield. At this stage, it can only be speculation as to which, or both, of the inseparable components of MS are moderately heritable. Cell numbers are likely to be determined by animal size and so may be related to the growth of the animal, although in the review of Veerkamp (1998), the genetic correlation of milk yield and mature weight ranged from -0.41 to +0.45 , with the majority of the results lying between +0.2 and -0.2 . The heritability of growth rate and size are also moderately heritable (Veerkamp, 1998). Milk secretion rate per cell is likely to be largely determined by energetic relationships in the cow. The genetic potential for cell secretion rate may not be met in commercial dairy herds, because milk production is determined by energy intake and body fat mobilization, within any given milking regimen.

Interestingly, MS is not genetically correlated with the relative death rate of secretory cells in late lactation. This is interesting for 2 reasons. First, it demonstrates that the 2 logistic curves used in the biological model were estimated independently of each other, a feature deemed to be important in lactation curve models (Morant and Gnanasakthy, 1989) but that does not happen with the Wood model. Second, the effect of apoptosis is independent from the development of maximum secretion rate and indicates that genetic selection programs could be developed that include separate terms for both phases of the lactation curve, appropriately weighted as determined by the desired outcome for the selection program. The relative death rate of cells is also moderately correlated with total milk yield and so may respond to selection independently of maximum secretion potential, despite having a low heritability. Not surprisingly, the relative cell death rate is highly genetically correlated with persistency, and therefore, selection on this parameter would lead to improved milk production via a more persistent lactation. Using such a model in dairy evaluations could lead to more precision in the way milk yield is improved, because it would allow independent selection for different aspects of the lactation curve.

\section{CONCLUSIONS}

Using a biological model of lactation to analyze commercial dairy records results in new lactation parameters. These parameters have been shown to be genetically controlled and linked to key features of milk production (e.g., total milk yield, persistency).

\section{ACKNOWLEDGMENTS}

The first author wishes to acknowledge the financial support of the National Council of Science and Technology and the Autonomous University of Mexico State toward his PhD program. National Milk Records Ltd. provided the data for this study and is gratefully acknowledged. The Sustainable Livestock Systems Group of the Scottish Agricultural College, Edinburgh, are acknowledged for the use of their facilities, in particular to Geoff Simm, Mike Coffey, Raphael Mrode, Eileen Wall, and Sue Brotherstone, of Edinburgh University, for their help during the genetic analyses.

\section{REFERENCES}

Batra, T. R., C. Y. Lin, A. J. McAllister, A. J. Lee, G. L. Roy, J. A. Vesely, J. M. Wauthy, and K. A. Winter. 1987. Multitrait estimation of genetic parameters of lactation curves in Holstein heifers. J. Dairy Sci. 70:2105-2111.

Davis, S. R., V. C. Farr, and K. Stelwagen. 1999. Regulation of yield loss and milk composition during once-daily milking: A review. Livest. Prod. Sci. 59:77-94.

Dijkstra, J., J. France, M. S. Dhanoa, J. A. Maas, M. D. Hanigan, A. J. Rook, and D. E. Beever. 1997. A model to describe growth patterns of the mammary gland during pregnancy and lactation. J. Dairy Sci. 80:2340-2354.

Falconer, D. S., and T. F. C. Mackay. 1996. Introduction to Quantitative Genetics. 4th ed. Longman, London, UK.

Farhangfar, H. 2002. A phenotypic and genetic study of lactation traits in Iranian Holstein cows. PhD Thesis. University of Newcastle upon Tyne, UK.

Gilmour, A. R., B. J. Goel, B. R. Cullis, S. J. Welham, and R. Thompson. 2002. ASReml User Guide Release 1.0. VSN International Ltd., Hemel Hempstead, UK. 
Grossman, M., and W. J. Koops. 1988. Multiphasic analysis of lactation curves in dairy cattle. J. Dairy Sci. 71:1598-1608.

Knight, C. H., M. Peaker, and C. J. Wilde. 1998. Local control of mammary development and function. Rev. Reprod. 3:104-112.

Knight, C. H., and C. J. Wilde. 1993. Mammary cell changes during pregnancy and lactation. Livest. Prod. Sci. 35:3-19.

Masselin, S., D. Sauvant, P. Chapoutot, and D. Milan. 1987. Les modèles d'ajustement des courbes de lactation. Ann. Zootech. 36:171-206.

Misztal, I. 2006. Properties of random regression models using linear splines. J. Anim. Breed. Genet. 123:74-80.

Morant, S. V., and A. Gnanasakthy. 1989. A new approach to the mathematical formulation of lactation curves. Anim. Prod. 49:151-162

Olori, V. E., S. Brotherstone, W. G. Hill, and B. J. McGuirk. 1999 Fit of standard models of the lactation curve to weekly records of milk production of cows in a single herd. Livest. Prod. Sci. 58:55-63.

Pollott, G. E. 2000. A biological approach to lactation curve analysis for milk yield. J. Dairy Sci. 83:2448-2458.

Pollott, G. E. 2004. Deconstructing milk yield and composition during lactation using biologically based lactation models. J. Dairy Sci. 87:2375-2387.

Pollott, G. E., and E. Gootwine. 2000. Appropriate mathematical models for describing the complete lactation of dairy sheep. Anim. Sci. 71:197-207.

Pollott, G. E., and E. Gootwine. 2001. A genetic analysis of complete lactation milk production in improved Awassi sheep. Livest. Prod. Sci. 71:37-47.

Sargent, F. D., V. H. Lytton, and O. G. Wall Jr. 1968. Test interval method of calculating Dairy Herd Improvement Association records. J. Dairy Sci. 51:170-179.

SAS Institute. 1999. User's Guide, Release 8.2. SAS Institute Inc., Cary, NC.
Schaeffer, L. R., and J. C. M. Dekkers. 1994. Random regressions in animal models for test-day production in dairy cattle. Proc. 5th World Congr. Genet. Appl. Livest. Prod. 18:443-446.

Schneeberger, M. 1981. Inheritance of lactation curve in Swiss Brown cattle. J. Dairy Sci. 64:475-483.

Shanks, R. D., P. J. Berger, A. E. Freeman, and F. N. Dickinson. 1981. Genetic aspects of lactation curves. J. Dairy Sci. 64:18521860.

Togashi, K., and C. Y. Lin. 2006. Selection for milk production and persistency using eigenvectors of the random regression coefficient matrix. J. Dairy Sci. 89:4866-4873.

Togashi, K., and C. Y. Lin. 2007. Genetic modification of the lactation curve by bending the eigenvectors of the additive genetic random regression coefficient matrix. J. Dairy Sci. 90:5753-5758.

Veerkamp, R. F. 1998. Selection for economic efficiency of dairy cattle using information on live weight and feed intake: A review. J. Dairy Sci. 81:1109-1119.

Vetharaniam, I., S. R. Davis, T. K. Soboleva, P. R. Shorten, and G. C. Wake. 2003. Modeling the interaction of milking frequency and nutrition on mammary gland growth and lactation. J. Dairy Sci 86:1987-1996.

White, I. M., R. Thompson, and S. Brotherstone. 1999. Genetic and environmental smoothing of lactation curves with cubic splines. J. Dairy Sci. 82:632-638.

Wilde, C. J., C. V. P. Addey, L. M. Boddy, and M. Peaker. 1995. Autocrine regulation of milk secretion by a protein in milk. Biochem. J. 305:51-58.

Wilde, C. J., L. H. Quarrie, E. Tonner, D. J. Flint, and M. Peaker. 1997. Mammary apoptosis. Livest. Prod. Sci. 50:29-37.

Wood, P. D. P. 1967. Algebraic model of lactation curve in cattle. Nature 216:164-165. 